\title{
DERECHOS DE LAS PAREJAS DEL MISMO SEXO A LA CONSTITUCIÓN DEL VÍNCULO MATRIMONIAL: ANÁLISIS DE ALGUNOS ARGUMENTOS EN CONTRA A LA LUZ DE LA PROPUESTA DE HABERMAS SOBRE EL ROL DE LA RELIGIÓN EN LA ESFERA PÚBLICA"
}

\author{
Javier Orlando Aguirre Román** \\ Ana Patricia Pabón Mantilla**
}

Recibido: Abril 30 de 2014 Aprobado: Mayo 30 de 2014

\section{RESUMEN}

El producto de investigación que se presenta propone una reflexión acerca de los argumentos constitucionales que justifican la garantía del derecho de las parejas del mismo sexo a constituir una familia mediante el vínculo del matrimonio y de los argumentos y acciones que se han propuesto como obstáculos para la realización de este derecho. Para analizar dicho problema se partirá de algunos aspectos de la filosofía de Habermas, en especial sus consideraciones sobre el papel de la religión en la esfera pública. La reflexión contenida en este producto se centra en la descripción de los argumentos que justifican el acceso al matrimonio por parte de las parejas del mismo sexo y de la evaluación de los

"El presente texto constituye una reflexión derivada de los resultados del proyecto de investigación titulado Análisis de la propuesta de Jürgen Habermas acerca del rol de la religión en la esfera pública. Tres casos de la jurisprudencia de la Corte Constitucional de Colombia, adelantado por el grupo de investigación Politeia de la Escuela de Filosofía de la Universidad Industrial de Santander, el investigador principal es el profesor Javier Orlando Aguirre Román, quien participa en calidad de coautor y es financiado por la Vicerrectoría de Investigación y Extensión(VIE) de la Universidad Industrial de Santander. El código del proyecto, el cual fue iniciado en diciembre de 2013, es 1376.

** Doctor y Magister en Filosofía de la State Univeristy of New York - Stony Brook, Especialista en Docencia Universitaria, Filósofo y Abogado. Profesor Asociado de la Escuela de Filosofía de la Universidad Industrial de Santander. Miembro del Grupo de Investigación Politeia, líneas de Filosofía Política y Filosofía del Derecho. Correo electrónico: jaguirre@uis.edu.co

Aspirante a Doctora en Derecho, Magister en Hermenéutica Jurídica y Derecho, Especialista en Docencia Universitaria, Filósofa y Abogada. Profesora Asociada de la Facultad de Derecho de la Universidad Autónoma de Bucaramanga UNAB, líder del grupo de investigación en Teoría del Derecho y Formación Jurídica y vinculada al grupo de investigación Politeia, línea de investigación en Filosofía Política y Filosofía del Derecho. Correo electrónico: apabon742@unab.edu.co 
argumentos que se han propuesto por los funcionarios del Estado y que han hecho difícil la garantía de este Derecho.

Palabras claves: Estado Constitucional, Democracia deliberativa, Espera pública, Corte Constitucional, Argumentos religiosos, Matrimonio igualitario, Parejas del mismo sexo.

\title{
HABERMAS' ACCOUNT OF THE ROLE OF RELIGION IN THE PUBLIC SPHERE AND SOME ARGUMENTS AGAINST MARRIAGE'S RIGHTS OF SAME - SEX COUPLES
}

\begin{abstract}
This research product expounds the constitutional arguments to favor and reject the institutionalization of same-sex marriages. These arguments are analyzed within the framework of Jürgen Habermas' account of the role of religion in the public sphere of a deliberative democracy, especially at the level of the juridical processes.
\end{abstract}

Key words: Constitutional State, Deliberative Democracy, Public Sphere, Constitutional Court, Religious Arguments, Same - Sex Marriage, Same-Sex Couples

\section{DIREITOS DE CASAIS DO MESMO SEXO DA CONSTITUIÇÃO DA RELAÇÃO DE ANÁLISE CIVIL ALGUNS ARGUMENTOS CONTRA A LUZ DO HABERMAS PROPOSTA SOBRE O PAPEL DA RELIGIÃO NA ESFERA PÚBLICA}

\section{RESUMO}

O produto da pesquisa apresentada propõe uma reflexão sobre os argumentos constitucionais para garantir o direito de casais do mesmo sexo para formar uma família através do vínculo do casamento e os argumentos e ações que têm sido propostas como obstáculos para a realização deste direito. Para analisar este problema vai deixar alguns aspectos da filosofia de Habermas, especialmente sua conta do papel da religião na esfera pública. A reflexão neste produto centra-se na descrição dos argumentos que justificam o acesso ao casamento por casais do mesmo sexo e a avaliação dos argumentos que têm sido propostas por funcionários do Estado e têm tornado difícil para garantir este direito. 
Palavras chaves: Estado Constitucional Democracia Deliberativa, espere Pública, do Tribunal Constitucional, argumentos religiosos, o casamento igualitário, casais do mesmo sexo.

\section{INTRODUCCIÓN}

Sin lugar a dudas el debate en torno a la necesidad de proteger los derechos de las parejas del mismo sexo en su libre opción de conformar una familia y formalizar su vida en pareja tuvo como antecedente relevante la Sentencia C- 075 de 2007 que generó la posibilidad de que las parejas del mismo sexo registraran sus uniones familiares de la misma forma en que ya lo hacían desde el 90 las parejas heterosexuales, a través de la unión marital de hecho. Sin embargo esta decisión fue suficiente frente a las garantías que se derivan del derecho a la igualdad y su prohibición de no discriminación por criterios sospechosos como la raza, el sexo o la orientación sexual.

En esa medida la Sentencia C- 577 de 2011 constituyó un nuevo avance frente a la protección del derecho a conformar una familia de la población LGBTI, población tradicionalmente discriminada. Si bien la Corte Constitucional en dicho pronunciamiento no resuelve sobre la exequibilidad de la norma acusada, exhorta al Congreso, por tratarse del escenario por excelencia para el desarrollo de la deliberación pública, a que regule el acceso de las parejas del mismo sexo al derecho al matrimonio como forma de conformar una familia.

El 20 de Julio del 2013 vencía el plazo para que el Congreso regulase la materia objeto de debate, sin embargo, una vez vencido el plazo propuesto por la Corte el proyecto de ley presentado a debate como intento por regular el matrimonio igualitario ante el legislador no logró los votos necesarios para regular mediante ley la posibilidad del matrimonio de parejas del mismo sexo.

Ante este panorama, la omisión del legislador activó la cláusula propuesta por la Corte en su decisión: "las parejas del mismo sexo podrán acudir ante notario o juez competente a formalizar y solemnizar su vínculo contractual" (Sentencia C- 577, 2011).

Sin embargo, el numeral quinto de la sentencia no permitió llegar "al vivieron felices para siempre", pese a que existen buenos argumentos para justificar la constitucionalidad de que jueces y notarios accedan a las solicitudes de las pareja del mismo sexo que desean formalizar sus 
relaciones de pareja muchos hechos y acciones han dificultado $\mathrm{u}$ obstaculizado la garantía de los derechos de las parejas del mismo sexo que se derivan de la Sentencia C-577 de 2011.

Buena parte de lo anterior se explica por la falta de unidad de criterio sobre la aplicación de la Sentencia del 2011 ante la omisión del legislador de regular el tema, pero esta no es la única explicación; se ha constituido una verdadera cruzada contra el matrimonio igualitario liderada, en buena parte, por la actuación de los funcionarios de la Procuraduría en concordancia con las directrices del jefe del Ministerio Público a los funcionarios de esta entidad, notarios y jueces, actuaciones todas que han dificultado el acceso de las parejas a su derecho fundamental a conformar una familia por los medios de que disponen sin dificultad alguna las parejas heterosexuales, lo que ha hecho que algunos notarios siguiendo dichas directrices hayan vulnerado derechos de las parejas que han solicitado reconocer sus uniones.

¿Qué argumentos se han propuesto en el debate que han terminado obstaculizando los derechos de las parejas del mismo sexo a constituir una familia mediante el matrimonio en los términos propuestos por la sentencia del 2011? ¿Cuáles de esos argumentos pueden hacer parte de la esfera pública de la discusión? El artículo que se presenta busca reflexionar sobre estos cuestionamientos a partir de los resultados de la investigación Análisis de la propuesta de Jürgen Habermas acerca del rol de la religión en la esfera pública. Tres casos de la jurisprudencia de la Corte Constitucional de Colombia, en lo que sigue se hará una precisión metodológica con el fin de pasar a la presentación de la discusión.

\section{APUNTE METODOLÓGICO}

La investigación de la que se deriva este producto busca desarrollar una interpretación sistemática y crítica de un aspecto de la filosofía de Habermas, referido a sus consideraciones en torno al papel de la religión en la esfera pública. Para ello se parte, de manera especial, de los conceptos de democracia deliberativa, sociedad mundial postsecular y pensamiento postmetafísico. La investigación propone desarrollar un análisis, a partir de este marco teórico - filosófico, de tres casos discutidos en la Corte Constitucional colombiana que han generado y siguen generando fuertes controversias, y en cuyo debate no se incorporan únicamente argumentos jurídicos, sino también religiosos y morales. 
Para este avance se tomará como referente el caso del matrimonio igualitario, cuya decisión hito es la Sentencia C-577 de 2011. Básicamente se parte de un análisis documental de tipo cualitativo, y para el presente texto se parte de la descripción de los resultados preliminares de forma analítica.

El presente texto tiene como finalidad dar cuenta de la discusión en dos niveles; en primer lugar analizar las razones constitucionales para garantizar los derechos de las parejas del mismo sexo a conformar una familia mediante el matrimonio, para lo que se expondrán los resultados de un análisis documental de las fuentes jurisprudenciales que sustentan el derecho al matrimonio como derivado del derecho al libre desarrollo de la personalidad. En un segundo momento se analizarán las acciones que han obstaculizado el ejercicio de las parejas del mismo sexo para acceder al matrimonio. En este punto se describirán los resultados de un análisis exploratorio de las diferentes fuentes que documentan estos hechos. Finalmente se analizará desde la perspectiva de Habermas, qué argumentos pueden incorporarse de manera legítima en este debate y en qué medida los argumentos religiosos que se enmascaran en las actuaciones de algunos funcionarios pueden hacer o no parte del debate.

En lo que sigue se presentarán los resultados parciales de la discusión.

\section{ARGUMENTOS PRO MATRIMONIO IGUALITARIO}

En este apartado se defenderá la tesis de que la opción del matrimonio, como parte del derecho a constituir una familia está amparada por derechos fundamentales como el libre desarrollo de la personalidad, y la negación de su disfrute constituye una violación de los mismos. De igual forma se partirá de que la interpretación que se haga del artículo 42 superior debe favorecer una protección amplia de todas las formas de familia, lo cual es coherente con los precedentes en la materia.

\subsection{El acceso al matrimonio como parte del derecho al libre desarrollo de la personalidad.}

El derecho fundamental al libre desarrollo de la personalidad, puede entenderse como "La potestad de cada cual para fijar esas opciones de vida de conformidad con las propias elecciones y anhelos, sin desconocer con ello los derechos de los demás y el ordenamiento jurídico existente" (Sentencia C-309, 1997). Este derecho, protegido constitucionalmente, "se manifiesta singularmente en la definición 
consciente y responsable que cada persona puede hacer frente a sus propias opciones de vida y a su plan como ser humano, y colectivamente, en la pretensión de respeto de esas decisiones por parte de los demás miembros de la sociedad"(Sentencia T- 668, 2005).

Las normas y actuaciones de los funcionarios que impliquen limitaciones desproporcionadas al derecho al libre desarrollo de la personalidad constituyen una intromisión en el fuero interno de las personas. La limitación de la decisión de una persona de realizar su proyecto de vida como pareja mediante el vínculo del matrimonio constituye una vulneración a su derecho fundamental al libre desarrollo de la personalidad.

Para la Corte "la Constitución opta por un orden jurídico que es profundamente respetuoso de la dignidad y la autonomía individuales (CP art. $1^{\circ}$ y 16), por lo cual, en principio, no corresponde al Estado ni a la sociedad sino a las propias personas decidir la manera en que desarrollan sus derechos y construyen sus proyectos de vida y sus modelos de realización personal" (Sentencia T-1011, 2001). Conforme a esto, las personas, a pesar de vivir en una comunidad reglada por unas convenciones sociales preestablecidas, pueden perfectamente actuar y sentir de una manera diferente a lo convencionalmente aceptado, siempre y cuando dicho actuar y sentir no vulnere derechos de los otros con quienes interactúan en comunidad.

Esto, evidentemente, incluye todos los casos en los cuales el actuar de una persona se enmarque en lo concerniente a sus aspiraciones y a la autodeterminación personal, como lo es el decidir qué modelo de vida desea desarrollar, sea como padre o madre, o como pareja.

La Corte puntualiza en la Sentencia del 2011 que la familia y el matrimonio son derechos fundamentales y que la constitución de una familia es "una manifestación del libre desarrollo de la personalidad y, en concreto, de la libre expresión de afectos y emociones", ya que "su origen se encuentra en el derecho de la persona de elegir libremente entre las distintas opciones y proyectos de vida, que según sus propios anhelos, valores, expectativas y esperanzas, puedan construir y desarrollar durante su existencia" (Sentencia C-577, 2011).

\subsection{La interpretación que debe guiar la protección de derechos como el de contraer matrimonio y conformar familia en el caso de las parejas del mismo sexo}


La omisión del legislador frente a la regulación de nuevas realidades sociales ha generado problemas de interpretación para asegurar la garantía de los derechos en igualdad de condiciones a las parejas homosexuales que han sido tradicionalmente discriminadas por la legislación colombiana. Para nadie es un secreto que la existencia de familias homosexuales es una realidad cuya no regulación deja desprotegidas a las personas que integran estas familias. Esta omisión interfiere en la elección de estas familias de optar por constituirse mediante vínculos jurídicos. La omisión del legislador ha generado que sea la Corte Constitucional quien proponga reglas con el fin de evitar que en el ordenamiento jurídico se mantengan discriminaciones injustificadas y dirigir la interpretación constitucionalmente válida para orientar al intérprete.

La interpretación que se haga de la Constitución en su artículo 42 debe ser coherente con las demás normas constitucionales que protegen a todas las personas habitantes del territorio colombiano sin distingo alguno, entre ellos la orientación sexual y deben ser coherentes con el principio de interpretación pro homine. El amplio universo de derechos individuales protegidos en la Carta que implican la garantía para que todas las personas desarrollen libremente su personalidad y orientación sexual permite afirmar que el campo de la libertad de opción frente a la conformación de una familia a través de un contrato matrimonial, también está protegida por esta esfera de derechos.

Con relación a las dificultades en torno a la interpretación que debe darse del alcance de la Sentencia C-577 de 2011, puede considerarse que a partir del principio pro homine debe favorecerse una interpretación de la sentencia que permita una amplia protección de los derechos de las parejas del mismo sexo que desean formalizar sus uniones. Entre dos interpretaciones posibles debe elegirse siempre aquella que sea más garantista de los derechos de las personas y de su dignidad. Desde ahí no hay razón para adoptar una interpretación restrictiva ni de la Sentencia del 2011 ni del artículo 42 en torno a la calificación de los sujetos que pueden celebrar el contrato de matrimonio y de la forma en que dicha unión se hace solemne. Debe acogerse una interpretación que incluya las diversas formas de familia, todas con protección constitucional, pues están conformadas por personas que no pueden ser discriminadas por su orientación sexual.

La Corte ha descartado la interpretación meramente literal del artículo 42 y reconoce que dicha norma debe tener en cuenta la evolución constante de las familias de tal modo que ha definido a la "familia "en un sentido 
amplio", como "aquella comunidad de personas emparentadas entre sí por vínculos naturales o jurídicos, que funda su existencia en el amor, el respeto y la solidaridad, y que se caracteriza por la unidad de vida o de destino que liga íntimamente a sus integrantes más próximos". En el mismo sentido ha afirmado la Corte "el concepto de familia no puede ser entendido de manera aislada, sino en concordancia con el principio de pluralismo", porque "en una sociedad plural, no puede existir un concepto único y excluyente de familia, identificando a esta última únicamente con aquella surgida del vínculo matrimonial" (Sentencia C577, 2011).

\subsection{La protección del matrimonio igualitario es coherente con el precedente constitucional}

Proteger el derecho que tienen las parejas del mismo sexo a contraer matrimonio es coherente con otros derechos protegidos mediante la jurisprudencia de la Corte Constitucional a las parejas homosexuales. Se reconoce el avance en materia de protección jurisprudencial a las parejas homosexuales en la jurisprudencia de la Corte, y al reconocimiento de una realidad social que debe ser regulada. Tal es el caso de la Sentencia C-075 del 2007 que estableció que tanto parejas heterosexuales como homosexuales, tienen unos requerimientos análogos de protección, y son de igual forma amparadas por las normas superiores constitucionales, pues las dos formas tienen igual valor y dignidad, lo que exige igual protección. Bajo este argumento se puede sustentar también la idea de que debe protegerse a las parejas homosexuales que tengan la intención de formalizar sus uniones a través del matrimonio, razón por la cual la Sentencia del 2011 es coherente con los precedentes en la materia y los funcionarios que no permitan la realización de la misma incurren en violación de derechos fundamentales de los solicitantes ${ }^{1}$.

\section{OBSTÁCULOS PARA LA REALIZACIÓN EFECTIVA DE LOS DERECHOS DE LAS PAREJAS DEL MISMO SEXO A ACCEDERAL MATRIMONIO}

Muchos han sido los obstáculos que han encontrado las parejas del mismo sexo para hacer efectiva la garantía constitucional de su derecho a conformar una familia mediante el vínculo del matrimonio. En primer

1 Sobre el desarrollo de la jurisprudencia de la Corte puede verse: Londoño Jaramillo, Mabel, (2012). Derechos de las parejas del mismo sexo Un estudio desde la jurisprudencia de la Corte Constitucional Colombiana, Revista Opinión Jurídica, vol. 11, núm. 22, julio-diciembre, 2012, pp. 45-64, Universidad de Medellín, Medellín, Colombia. 
lugar la derrota legislativa del proyecto de ley que regulaba el matrimonio igualitario, hasta el punto de que al 20 de Julio de 2013 se venció el plazo que propuso la Corte Constitucional para que el Congreso regulara la materia y se activara la cláusula quinta de la Sentencia del 2011.

Sin embargo este no fue el mayor obstáculo, el principal foco de dificultad se ha concentrado en las actuaciones de la Procuraduría, pues desde la jefatura del Ministerio Público se ha iniciado toda una cruzada que ha dificultado la eficacia de la protección constitucional conferida a las parejas del mismo sexo mediante la Sentencia del 2011. La actuación de procuradores judiciales y del mismo procurador general mediante sus directrices ha dificultado el acceso de las parejas del mismo sexo a su derecho al matrimonio igualitario.

La Procuraduría a través de sus diversos funcionarios ha cuestionado el equilibrio de poderes y el control legítimo que debe darse entre las diferentes ramas del poder público al hacer afirmaciones desobligantes en donde, por ejemplo, el jefe del Ministerio en un discurso en la Jornada Internacional del Derecho Notarial, realizada en Cali, afirmó que la Corte Constitucional tomó una "decisión confusa, contradictoria y farragosa". Según el Procurador, el argumento de la Corte fue "falaz y artificioso" 2 . Este hecho ha sido resaltado por otros funcionarios del Estado como es el caso del Fiscal General, quien afirmó que la Procuraduría con sus actuaciones frente al matrimonio igualitario estaría cometiendo una "transgresión de tipo penal por extralimitación de poder y abuso de autoridad" (El Tiempo, 2013).

La Procuraduría tiene como finalidad contribuir con la protección y garantía de los derechos de todas las personas que residen en el Estado colombiano; sin embargo para el caso de las parejas del mismo sexo que han optado libremente por solicitar formalizar sus uniones mediante el vínculo matrimonial, el mismo organismo ha empleado diferentes acciones para obstaculizar su derecho.

Uno de esos recursos ha sido el de interponer acciones de tutela contra las decisiones de jueces que han accedido a las solicitudes de matrimonio interpuestas por parejas del mismo sexo. La tutela frente a estos casos no solamente es un mecanismo improcedente, pues existe la acción de nulidad que deja en competencia del juez de familia la facultad de resolver sobre la nulidad del matrimonio.

2 Se puede ver el video. Recuperado de http://www.youtube.com/watch?v=-PEjvOyP_Gc Citado por Colombia Diversa en www.colombiadiversa.org 
¿Qué argumentos están detrás de las actuaciones de la Procuraduría? La ideología del procurador se puede deducir de algunas de sus publicaciones $^{3}$, sin embargo no son estos textos los que más trascendencia tienen, sino las intervenciones que como jefe del Ministerio Público hace en virtud de sus funciones.

\subsection{Las intervenciones de la Procuraduría frente al matrimonio igualitario}

En la intervención del Jefe del Ministerio Público en la Sentencia C-577 de 2011 el Procurador defiende la tesis de que la heterosexual es "la única familia que goza de protección constitucional y que el matrimonio solo puede entenderse como fuente jurídica de la familia", argumento que se presenta en favor de la constitucionalidad de la norma acusada.

El Procurador, en torno a la interpretación del artículo 42 de la Constitución señala que no se puede deducir otra cosa diferente a que el matrimonio requiere para su conformación la voluntad de un hombre y una mujer, en ese sentido, citando un pronunciamiento anterior formula la pregunta en torno a:
¿Qué justificación podría tener que el Constituyente hubiese hecho expresa y específica referencia a un hombre y una mujer, si al mismo tiempo quería que la familia se conformara por la simple voluntad de cualquier persona o personas (ya fuera un hombre, una mujer, un hombre y un hombre, una mujer y una mujer o hasta de un hombre o una mujer con un animal o una cosa? (Sentencia C-577, 2011).

Para el Procurador el anterior interrogante y otros del mismo tipo, permiten demostrar que la familia no puede constituirse por personas de distinto sexo. El matrimonio, desde el concepto de la Procuraduría ha sido configurado por la Constitución a partir de unos elementos esenciales:

(i) ser institución jurídica, (ii) ser relación familiar, (iii) ser relación jurídica, (iv) constituirse mediante un vínculo jurídico único y mutuo, (v) ser derecho fundamental, (vi) vincular o unir jurídicamente a un hombre y a una mujer, (vii) generar derechos y deberes entre los cónyuges, y (viii) estar

3 Entre los libros de autoría del procurador Alejandro Ordóñez se encuentran La Unión Homosexual: Hacia el libre desarrollo de nuestra animalidad, Ideología de género: utopía trágica o revolución cultural y su tesis de pregrado: Presupuestos fundamentales del Estado católico. 
abierto a la procreación y a la educación de los hijos, así como a la realización de las personas de los cónyuges. (Sentencia C577, 2011). (Subrayado fuera del texto)

¿Cuáles son los problemas de este argumento? Si se aceptara como una finalidad esencial del matrimonio estar abierto a la procreación se podría concluir que a la institución del matrimonio sólo pueden acceder parejas heterosexuales fértiles que tengan la intención de tener hijos, de tal suerte que ante un problema de infertilidad de la pareja heterosexual debería estar dispuesto a asumir un tratamiento médico para facilitar la procreación y el Estado, cuyo deber es garantizar el acceso al matrimonio como derecho fundamental, debería de igual modo estar dispuesto a asumir el costo de proveerlo. Sin embargo, si el tratamiento no es exitoso las partes podrían revisar la validez del matrimonio pues es uno de los fines esenciales. ¿Podría el Estado pedir la anulación del matrimonio por no cumplir con ese fin, luego de que se verifique que invirtió sus recursos en un tratamiento que no fue exitoso?

La anterior es una situación hipotética, que no se da en el ordenamiento jurídico colombiano, pues la procreación no es una finalidad esencial del matrimonio que afecte la validez del contrato. Constituir una familia, vivir juntos, auxiliarse y socorrerse mutuamente, son entre otras finalidades del matrimonio, que puede cumplir cualquier pareja, incluidas las del mismo sexo.

¿Qué motiva el que se defina que la familia es únicamente la heterosexual? ¿Qué justifica que sea un fin esencial del matrimonio estar abierto a la procreación? Es posible que sean doctrinas religiosas las que valoren al matrimonio como una institución jurídico - política religiosa cuya naturaleza debe ser interpretada según los principios religiosos de la mayoría de la sociedad.

Esta posibilidad permite abordar la pregunta acerca de qué tipos de argumentos religiosos son admisibles en el seno del debate jurídico y político en torno al derecho al matrimonio de las parejas del mismo sexo.

\subsection{Argumentos religiosos en el debate en torno al matrimonio igualitario}

En general pueden identificarse dos posiciones extremas en torno al debate sobre la admisibilidad de los argumentos religiosos en el debate político y jurídico sobre el matrimonio igualitario. Por una parte se identifican los argumentos de quienes consideran que el matrimonio es 
una institución exclusiva de las parejas heterosexuales pues así corresponde con su naturaleza religiosa. Desde esta visión, todas las autoridades del Estado, en las distintas esferas de poder, Ejecutivo, Legislativo, Judicial, así como quienes ejercen la función pública como los notarios, deberían actuar conforme a los preceptos religiosos de la mayoría para quien se ha legislado el matrimonio monógamo y heterosexual.

En la otra esfera de la discusión se ubican las personas que defienden con base en el principio de laicidad del Estado, que los anteriores argumentos no deben incluirse en el debate, pues la religión es un asunto del ámbito privado que no tiene lugar en los sistemas democráticos. El argumento religioso que incluye razones para validar o invalidar un matrimonio igualitario o para definir la esencia del matrimonio puede incorporarse en la esfera pública de la discusión, en ninguno de los poderes y en ninguna de las actuaciones del Estado.

Estas dos posiciones pueden ser valoradas como extremas, cada una de las cuales tiene problemas en el contexto del sistema democrático. La primera, porque desconoce el pluralismo político y moral que ha protegido la Carta Política del 91 y que termina excluyendo las decisiones y elecciones no compartidas por los ciudadanos no religiosos; y la segunda porque al igual que la primera desconoce a una parte de la población, que tiene valores religiosos que se incorporan en la deliberación política porque hacen parte de su forma de ver la vida no sólo en lo privado. El ejercicio de lo religioso también es protegido por la Carta del 91 cuando se reconocen los derechos a la libertad de cultos y a actuar conforme a las razones de conciencia.

La construcción de una democracia necesita una posición menos inflexible para abordar los argumentos religiosos de sus ciudadanos. Habermas propone una revaloración acerca del papel de la religión en la democracia. La democracia deliberativa supone, en palabras de Habermas que:

El procedimiento democrático debe su fuerza generativa de legitimación a dos componentes: por un lado, a la participación política igualitaria de los ciudadanos, que garantiza que los destinatarios de las leyes puedan también entenderse a sí mismos al mismo tiempo como los autores de esas leyes; $y$, por otro lado, a la dimensión epistémica de las formas de discusión y de acuerdo dirigidas deliberativamente, 
que justifican la presunción de resultados racionalmente aceptables. (Habermas, 2006, p. 128).

Para Habermas, se pueden distinguir dos niveles en los que se desarrollan discusiones, el nivel de la "esfera pública informal", en donde los participantes deben cumplir ciertos requisitos, para que su discurso sea libre, informado, $\mathrm{y}$, fundamentalmente, democrático.

Un segundo nivel es el de la "esfera pública formal", que corresponde al nivel institucional del Congreso, los jueces y cortes y en general la administración del Estado y de la función pública. En este nivel todo tiene que ser expresado en un lenguaje claro a los ciudadanos y los argumentos religiosos no serían aceptables para sustentar una ley o política aplicable de forma general a todos los ciudadanos.

Ahora, esto no quiere decir que los argumentos religiosos no deban ser escuchados, este tipo de argumentos debe encontrar traducciones que permitan ser incorporados en los debates de la esfera pública formal.

¿Qué argumentos religiosos pueden ser traducidos para ser tenidos en cuenta en la toma de decisiones del Estado, garantizando los principios democráticos de la igualdad y la dignidad, y por el contrario qué argumentos deben ser excluidos?

\subsection{La cruzada contra el matrimonio igualitario}

COLOMBIA DIVERSA, una de las organizaciones no gubernamentales más representativa que trabaja en favor de los derechos de lesbianas, gays, bisexuales y transgeneristas (personas LGBT) en Colombia, ha hecho un seguimiento a las actuaciones de la Procuraduría y relata cómo durante el segundo semestre de 2013, después de que se venciera el plazo de la Sentencia del 2011, la Procuraduría inició acciones por diversas vías para frenar los alcances de la sentencia de la Corte.

Entre esas actuaciones se incluye por ejemplo la carta que dirigió el Procurador al Superintendente de Notariado y Registro en el cual solicita que los notarios se abstengan de celebrar matrimonios, y se limiten a celebrar contratos innominados para formalizar las uniones de parejas del mismo sexo.

En su misiva la Procuraduría señala: 
Se exhorta a las autoridades administrativas para que respeten las funciones del legislador y se abstengan de crear e imponer instituciones jurídicas inexistentes y, mucho menos, en desmedro de los derechos fundamentales y de la protección integral que, de conformidad con la Constitución, se debe brindar al matrimonio y a la familia ${ }^{4}$. (Procuraduría, Oficio del 22 de abril del2013).

En ese mismo sentido se promulgó la Circular 03 de 2013 de tal forma que bajo la directriz de "proteger" a la familia, los procuradores judiciales han intervenido en las solicitudes de matrimonio igualitario que se han presentado ante los jueces del país y se han interpuesto acciones de tutela para solicitar la nulidad de las actuaciones de los despachos.

Un acción a gran escala da muestras del control que ha iniciado la Procuraduría y radica en la orden expedida por el Ministerio Público para que las autoridades judiciales y notarios que tengan información sobre solicitudes de matrimonio igualitario informen datos personales de los solicitantes, testigos y del contenido mismo de la solicitud.

Cabe preguntarse, ¿la directriz de proteger la familia heterosexual como única forma de familia constituye un argumento religioso? Ordóñez pertenece a comunidades radicales dentro de la Iglesia Católica que manifiestan un fuerte rechazo a la homosexualidad. Esas posiciones se dejan ver con claridad en su libro 'El Desarrollo de nuestra animalidad', sin embargo en las directrices y comunicados se ha hecho una defensa desde argumentos que parecen estrictamente jurídicos, pese a que su motivación no se identifique como tal.

En sus argumentos llama a los notarios a ajustarse a la ley en estricto sentido, a interpretar la Sentencia del 2011 y el artículo 42 de la Carta de manera restrictiva, distingüendo que no se viola el derecho de las parejas del mismo sexo a constituir una familia cuando se les autoriza realizar un contrato innominado diferente al matrimonio. Sin embargo Ordoñez ha sido cuestionado en muchas oportunidades y escenarios, incluso en el escenario judicial mediante tutelas en su contra, por realizar actos públicos con contenido religioso $\mathrm{o}$, como se ha denominado, de proselitismo religioso en virtud de la posición que le provee su cargo.

4 El texto original de la carta. Recuperado de http://jkrincon.files.wordpress.com/2013/12/carta-procu-asupernotario-posicion-matrimonio-mayo-2013.pdF 


\section{CONCLUSIONES}

Para el caso objeto de análisis, se debe concluir que otorgar un tratamiento a las parejas homosexuales que limite su derecho a formalizar sus relaciones de pareja mediante el matrimonio, genera una situación de derecho diferente con relación a las parejas heterosexuales, generando con ello una evidente discriminación por razones de orientación sexual.

La decisión de la Corte constituye el reconocimiento jurídico de la realidad de las parejas homosexuales y de la opción por formalizar su vida en pareja mediante el vínculo matrimonial, generando ante el vacío de protección legal a las parejas homosexuales y en especial de la violación del legislador del deber constitucional de otorgar un mínimo de protección a las parejas homosexuales, que han sido excluidas de un régimen de protección y del régimen de obligaciones que impone el contrato matrimonial. El trato diferenciado es injustificado y vulnera su derecho a la igualdad, a no ser discriminados (Art. $13 \mathrm{CP}$ ), el derecho al libre desarrollo de la personalidad (Art. $16 \mathrm{CP}$ ), a la intimidad personal y familiar, y a la dignidad.

Ahora, respaldar el derecho que la Corte Constitucional les ha reconocido a las parejas del mismo sexo con base en los principios de la igualdad y la dignidad humana no implica de ninguna forma la expulsión o el menosprecio de la religión y de los argumentos de los ciudadanos religiosos, lo que sí exige es que los funcionarios del Estado en ejercicio de la discusión en la esfera formal deban asumir la carga de la argumentación conforme a la traducción de dichos argumentos, los cuales se deben ajustar a la interpretación del ordenamiento constitucional.

Ciertamente las tesis de la Procuraduría frente al matrimonio igualitario no deben ser rechazadas porque se acusen de parecer cercanas a la visión religiosa del Jefe del Ministerio Público, sino por constituir directrices poco fundamentadas en la interpretación autorizada de la Constitución, promovida por la Corte, y que se presentan, al defender la familia heterosexual como única forma de familia, como incompatibles con el pluralismo y el igualitarismo de nuestros principios constitucionales.

\section{REFERENCIAS BIBLIOGRÁFICAS}

Aguirre, J. (2012). Habermas y la religión en la esfera pública. Ideas y Valores, Vol. LXI (148), 59 - 78. 
Baumeister, Andrea. (2011). The Use of "Public Reason" by Religious and Secular Citizens: Limitations of Habermas Conception of the Role of Religion in the Public.

Colombia. Corte Constitucional. Sentencia C- 577 de 2011. (Magistrado Ponente: Gabriel Eduardo Mendoza Martelo. 26 de Julio de 2011)

Colombia. Corte Constitucional. Sentencia C-309 de 1997. (Magistrado Ponente: Alejandro Martínez Caballero. 25 de Junio de 1997)

Colombia. Corte Constitucional. Sentencia T- 668 de 2005. (Magistrado Ponente: Clara Inés Vargas Hernández. 30 de Agosto de 2005)

Colombia. Corte Constitucional. Sentencia T-1011 de 2001. (Magistrado Ponente: Alfredo Beltrán Sierra. 20 de Septiembre de 2001)

Colombia. Procuraduría General de la Nación. Circular 03 de 2013.

Cooke, M. (2006). Salvaging and secularizing the semantic contents of religion: the limitations of Habermas's postmetaphysical proposal. International Journal of Philosophy of Religion (60), 187-207.

Garzón, Iván. (2012). Deliberación democrática y razones religiosas: objeciones y desafíos Revista Co-herencia, Vol. 9(16), 81-117.

Habermas, J. \& Ratzinger, Joseph. (2008). Entre razón y religión. Dialéctica de la secularización. México: Fondo de Cultura Económica.

Habermas, J. (2001). Israel o Atenas. Ensayos sobre religión, teología y racionalidad. España: Trotta.

Habermas, J. (2002). El futuro de la naturaleza humana ¿Hacia una eugénesis liberal? España: Paidós.

Habermas, J. (2006). Entre naturalismo y religión. España: Paidós.

Habermas, J. (2009). ;Ay Europa!. España: Trotta.

Habermas, J. (2010). El concepto de la dignidad humana y la utopía realista de los derechos humanos. Diánoia, Vol. LV(64), 3-25. 
Habermas, J., et al. (2010). An Awareness of What is Missing. Faith and Reason in a Post-Secular Age. Estados Unidos - Reino Unido: Polity.

Habermas, J., et al. (2011). El poder de la religión en la esfera pública. España: Trotta.

Lafont, C. (2009). Religion in the Public Sphere. Philosophy and Social Criticism, Vol 35/(1-2), 127-150.

Lafont, Cristina. (2007). Religion in the Public Sphere: Remarks on Habermas's Conception of Public Deliberation in Post-secular Societies. Constellations, 14(2), 239-59. doi: 10.1111/j.14678675.2007.00436.x

Lemaitre, Julieta. (2009). Anti-clericales de nuevo: La Iglesia Católica como un actor político ilegítimo en materia de sexualidad y reproducción en América Latina. Derecho y Sexualidades, 286-304.

Londoño, Jaramillo Mabel. (2012). Derechos de las parejas del mismo sexo Un estudio desde la jurisprudencia de la Corte Constitucional Colombiana. Revista Opinión Jurídica, Vol. 11(22), 45-64.

Rueda, María Isabel. (2013, 6 de mayo). Alejandro Ordóñez no aspirará a la Presidencia. Recuperado de http://www.eltiempo.com/ politica/ARTICULO-WEB-NEW_NOTA_INTERIOR-12781222.html 